\title{
Community Awareness, Perceptions, Enablers and Potential Barriers to Non-Pharmaceutical Interventions (NPIs) in the COVID-19 Pandemic in Rivers State, Nigeria
}

\author{
Golden Owhonda ${ }^{1 *}$, Nnaana Onyekwere ${ }^{2}$, Rogers B Kanee ${ }^{3}$, Omosivie Maduka ${ }^{4}$, Ifeoma \\ Nwadiuto $^{5}$, Chinenye Okafor ${ }^{5}$, Ojimah Chibianotu ${ }^{5,6}$ and Eric Osamudiamwen Aigbogun ${ }^{7}$ \\ ${ }^{1}$ Rivers State Ministry of Health, Port Harcourt, Nigeria
}

${ }^{2}$ Africa Environmental and Human Development (AFRIDA), Port Harcourt, Nigeria

${ }^{3}$ Institute of Geo-science, Rivers State University, Port Harcourt, Nigeria

${ }^{4}$ Department of Preventive and Social Medicine, University of Port Harcourt, Nigeria

${ }^{5}$ World Health Organization (WHO), Rivers State, Field office, Port Harcourt, Nigeria

${ }^{6}$ Department of Epidemiology, University of Port Harcourt School of Public Health, Nigeria

${ }^{7}$ Center for Occupational Health, Institute of Petroleum Studies, University of Port Harcourt, Port Harcourt, Nigeria

*Corresponding author: Golden Owhonda, Rivers State Ministry of Health, Port Harcourt, Nigeria

\section{ARTICLE INFO}

Received: 幽 June 17, 2021

Published: 幽 July 02, 2021

Citation: Golden Owhonda, Nnaana Onyekwere, Rogers B Kanee, Omosivie Maduka, Ifeoma Nwadiuto, et al., Community Awareness, Perceptions, Enablers and Potential Barriers to Non-Pharmaceutical Interventions (NPIs) in the COVID-19 Pandemic in Rivers State, Nigeria. Biomed J Sci \& Tech Res 36(5)-2021. BJSTR. MS.ID.005928.

Keywords: COVID-19; Perception; Awareness; Non-Pharmaceutical Intervention; FGD: Focus Group; Community

Abbreviations: NPIs: Non-Pharmaceutical Interventions; IPC: Infection Prevention and Control; FGD: Focal Group Discussion; NCDC: Nigeria Centre for Disease Control

\section{ABSTACT}

Background: There are evidence that Non-Pharmaceutical Interventions (NPIs) reduce COVID-19-related morbidity and mortality across different regions. Nevertheless, there is poor compliance to the COVID-19 NPIs among residents, especially in the second wave of COVID-19 in Nigeria. This study, therefore, explored the awareness, perception, enablers and potential barriers that influence compliance to the COVID-19 NPIs among the youth and adult population of Rivers State, Nigeria.

Materials and Methods: This was a qualitative study that used twelve (12) focus groups, which comprised of a total of 120 participant (aged 18 - 60 years) during the Christmas festivity period $\left(18^{\text {th }}-20^{\text {th }}\right.$ December 2020). Focus group exercise took place physically across 12 randomly selected districts in the three Senatorial Zones of Rivers State, Nigeria. The participants were of diverse socio-demographic characteristics of gender, ethnic, age and occupational and trade and social groups of Thematic analytical methods were used to analyse audio recordings.

Results: The study found high community awareness of COVID-19 with low perceived risk of contracting SARS-CoV-2. Their major sources of information were town-criers and conventional media platforms such as radio, with little mention of social media and community opinion leaders' influence. Poor compliance to NPIs were largely attributed to perception which was influenced by their belief of the non-existence of the virus; with emphasis on - no physical evidence of survivals and victims, social stigma, distrust of the authorities, incoherent policies, and lack funds to afford a mask.

Conclusion: The high community awareness of COVID-19 virus was not a factor for positive public health behavioural change and compliance to NPIs. Perception borne from their current belief system can further complicate the efforts to ensure reduction in COVID-19 transmissions rate. The need for social medial platforms to influence behavioural change in communities cannot be overemphasized and should be strategically utilized. The study advises the need to NGOs and CSOs to produce and encourage the use of locally made reusable facemasks to reduce further escalation of the virus transmission. 


\section{Introduction}

Severe Acute Respiratory Syndrome Coronavirus 2 (SARSCoV-2) is the causative agent for COVID-19. First identified in Wuhan China in December 2019, over 102 million cases and 2.2 million deaths have been reported from 222 countries and territories as of 3rd Feb. 2021 [1]. In Nigeria, over 133,552 cases and 1,613 deaths have been documented across 36 States and the Federal Capital Territory, with 5,483 cases and 84 deaths recorded in Rivers as of 3rd Feb. 2021 [2]. While the COVID-19 pandemic continues to impose high mortality and morbidity burden across the world, public perception and acceptable community risk communication strategy remains vital in curtailing the pandemic [3]. Especially in Nigeria where misconceptions and disbelieves about the disease exists [4] and compliance to Infection Prevention and Control (IPC) protocols within communities and in public places have been observed to be low [5].

SARS-CoV-2 spreads through three common process [6]; direct or indirect contact transmission, respiratory droplet transmission and aerosol transmission. The direct contact transmission results from contact with an infected person, through a handshake. Indirect contact involves touching a contaminated inanimate object, like surfaces $[7,8]$. Droplets having the virus may project for distances up to 2 meters when an infected person sneezes, coughs or talks. Aerosolised droplets remain suspended in the air for some time and could travel farther distances $[9,10]$. Being a novel disease, the absence of an effective treatment and initial absence of a vaccines led sustained transmission causing huge socio-economic and health impact, necessitating countries to institute Non-Pharmaceutical Interventions (NPIs) such as hand hygiene, compulsory use of face masks, surface and object cleaning, quarantine, isolation, lock down, travel ban and restrictions [11-15]. Studies found a relationship between non-pharmaceutical interventions and decreased COVID-19 related mortality and morbidity in China, Europe and other part of the world [15-20]. There is evidence that people actively evaluate the NPIs using criteria such as perceived necessity, efficacy, acceptability, and feasibility [21]. Challenges such as lack of trust in government, strains in family resources, gaps and confusions in some areas of pandemic information communication and low adherence to voluntary social isolation and NPIs for public gatherings [22-26]. Surprisingly, Oyeyemi et al. found that Nigerians did not exhibit self-perceived risk of contracting COVID-19 [27]; thus, were not overly concerned about the events of the pandemic [28]. The study explored community awareness, attitude towards COVID-19 disease and compliance to NPIs among of residents of Rivers State.

\section{Material and Methods}

\section{Study Design and Setting}

The study employed a qualitative research design using Focal Group Discussion (FGD). The FDG was designed as an open-ended question as recommended in the IFRC/UNICEF FGD guide for communities. The method gives the room for stimulating an informal discussion with participants to understand their perceptions, beliefs, fears, questions and information needs with regards to the new coronavirus outbreak [29]. The data obtained are integrated into a meta-inference which did not need variable manipulation; thus, the study described and documented the various aspects of a situation as it naturally state [30-32]. The study population comprised adult males and female within the age range 19 to 60 years, who were indigenous residents in communities of the three (3) Senatorial Districts of Rivers State, Nigeria. Twelve physical focus groups with 10 participants each were ran between 18th and 20th December 2020. Since the research was a phenomenological study investigating structures of experience and consciousness, the sample size and distribution were within recommended limits $[33,35]$ to allow for generalization.

Sample selection was by a combination of targeted (purposive) and random sampling methods [36-38]. Firstly, the three senatorial zones in the State were identified, and LGAs in each senatorial zone and then communities in each LGA identified. The rural and urban communities in each senatorial zone were also identified. Communities, men, women and youths and other groups were randomly selected for the FGD for the FGD through public focal persons across the respective LGAs. The communities and groups involved include Women in Bori, Khana LGA, Khana LGA, Buguma in Asari-Toru LGA, Rumuokoro in Obio-Akpor LGA, Abali Motor Park in Port Harcourt LGA, Degema in Degema LGA, Ahoada in Ahoada East LGA, Omagwa in Ikwerre LGA, Egbo Etche in Etche LGA, Youths in Kira community of Tai LGA, Omoku in Ogba Egbema Ndoni LGA, Eleme in Eleme LGA, Female undergraduates in Bori, Khana LGA (Table 1). Conducive environments were identified prior to the FGDs. Formalities which included self-introduction, explanation of the purpose of the FGD were ensured. Prior to having each of the sessions, permission to record the session on audio tape was sought and confidentiality guaranteed. There were three (3) facilitators for each session (moderator, recorder and observer) that facilitated the discussions and took notes using the topic guide.

The participants were allowed and encouraged to freely express their opinions without any inhibition or fear of embarrassment or repercussion. Each discussion session lasted between 60 and 90 minutes. The recorded audio tapes were later transcribed and analysed with the notes taken during each of the discussion sessions. Data were collected within 3-days respectively across the three senatorial districts of the State; during the Christmas - eve when compliance to IPC and other non-pharmaceutical public health measures among the public was observed to be very poor amidst COVID-19 second wave in Nigeria, with Rivers State recording high daily positive case of COVID-19 [39]. In pandemic and emergency setting, such as the COVID-19 pandemic, online focus group discussions are recommended for obtaining community 
perceptions public health, particularly from geographically dispersed participants and diverse [40-42]. However, because of challenges of power, hard-to-reach locations, access to interment, and online adaptable devices faced by indigenous people, in-person focus group was used in the study to obtain data from the target group who constitute majority of population most susceptible to risk and influences public opinions. Social distance of 2 meters, wearing of facemasks and use of hand sanitizers were assured and ensure safety and infection prevention.

Table 1: Sociodemographic information reported by the participants.

\begin{tabular}{|c|c|c|}
\hline Characteristics & Distribution (n) & Age $($ Mean \pm SD) \\
\hline \multicolumn{3}{|c|}{ Gender } \\
\hline Male & 59 & $41.20 \pm 14.08$ \\
\hline Female & 61 & $42.23 \pm 13.70$ \\
\hline \multicolumn{3}{|c|}{ Occupation/trade } \\
\hline Market women & 33 & \\
\hline Motor Park men/drivers & 22 & \\
\hline Students/youths & 20 & \\
\hline Community leaders & 25 & \\
\hline The clergy & 9 & \\
\hline Teachers & 4 & \\
\hline Shop owners & 7 & \\
\hline \multicolumn{3}{|c|}{ Locations } \\
\hline Ahoada (Ahoada) & 10 & \\
\hline Asaritoru LGA (Buguma) & 10 & \\
\hline Degema (Degema) & 10 & \\
\hline Eleme (Ogale) & 10 & \\
\hline Etche LGA (Egbo) & 10 & \\
\hline Gokana LGA (Bori) & 10 & \\
\hline Khana (Bori) & 10 & \\
\hline Ikwere LGA (Omagwa) & 10 & \\
\hline Obi-akpor LGA (Rumuokoro) & 10 & \\
\hline Ogba/Egbema/Ndoni (Omoku) & 10 & \\
\hline Port Harcourt LGA (Abali park) & 10 & \\
\hline Tai LGA (Kira) & 10 & \\
\hline
\end{tabular}

\section{Ensuring Rigour}

Validity of the questionnaire were achieved through face, and content validations. The study instrument was developed using the IFRC/UNICEF FGD guide for communities [43]; however to assure localization of instrument, the questionnaire samples were sent to community engagement experts from different NGOs for their collective opinions which was subsequently reflected. The reliability was achieved through the sharing of the obtained recording to participants for member checking and respondent validation, to authenticate the results thereby increasing the credibility of the report [44]. One-day refresher training was conducted for facilitators, were tool and study protocol integrating COVID-19 setting were described. Study tool development, data collection and analysis were conducted by different sets of people. This was done to minimize bias and fatigue. Recorders (Sony ICD-PX470 Stereo Digital Voice Recorder with Built-in USB Voice Recorder, Black) were pre-tested before use and note taking as well as phone recording used simultaneously as back up to prevent loss of data.

\section{Ethical Considerations}

The study was conducted in line with the IFRC/UNICEF FGD guide [44] and the Helsinki declaration for studies involving human participation [45,46]. Ethical clearance was obtained from the Rivers State Ministry of Health's Ethics Committee (Department of Planning, Policy, Research and Statistics) and presented to the Community representatives and leaders. Verbal clearance were obtained from community leaders and signed informed consent was acquired from each study participants involved in the study. Before obtaining consent from participants, details about the study were explained and the participants were informed about their right to withdraw from the study, the risk, benefits, privacy and confidentiality involved in their participation. Although, the study did not make provision for financial gratification for participating in the study, nevertheless, to encourage compliance to NPIs, masks, and hand sanitizers were shared to the participants.

\section{Data Collection, Management and Analysis}

Data for the assessment was collected using an instrument developed by the State Ministry of Health and CHAI Nigeria, covering the goals and objectives of the assessment. The data were collected simultaneously across the selected communities/LGAs. A set of 3 FGD facilitators operated in each senatorial district. Discussions were recorded using a Digital Sony Recorder with Built-in USB Voice Recorder (ICD-UX570; Black, China) and backed up with paper recording by the recorders. Through rigorous and thematic coding, collected audio data were analysed following an iterative process, whereby emerging themes from early focus groups were used to add to or refine questions used for probing during subsequent focus group discussions. All focus groups were audio recorded and transcribed for coding [47]. Thematic analytical method was used in analyzing the data obtained from the study. Preliminary broad study questions inform the abductive generation of themes. Primary codes were developed and were then developed and interrelated themes connected to form predominant secondary codes that were developed into the five broad themes. Analysis continued until no new significant themes emerged $[48,49]$. 


\section{Results}

The qualitative data displayed five (5) themes from the 12 Focus Group Discussions (FGD). The themes topics ranged from behaviour and attitude, identifying enablers and potential barriers and messaging platforms for promoting COVID-19 messages and programs. The five themes (Figure 1) are described below with some verbatim samples of the participants' representative responses.

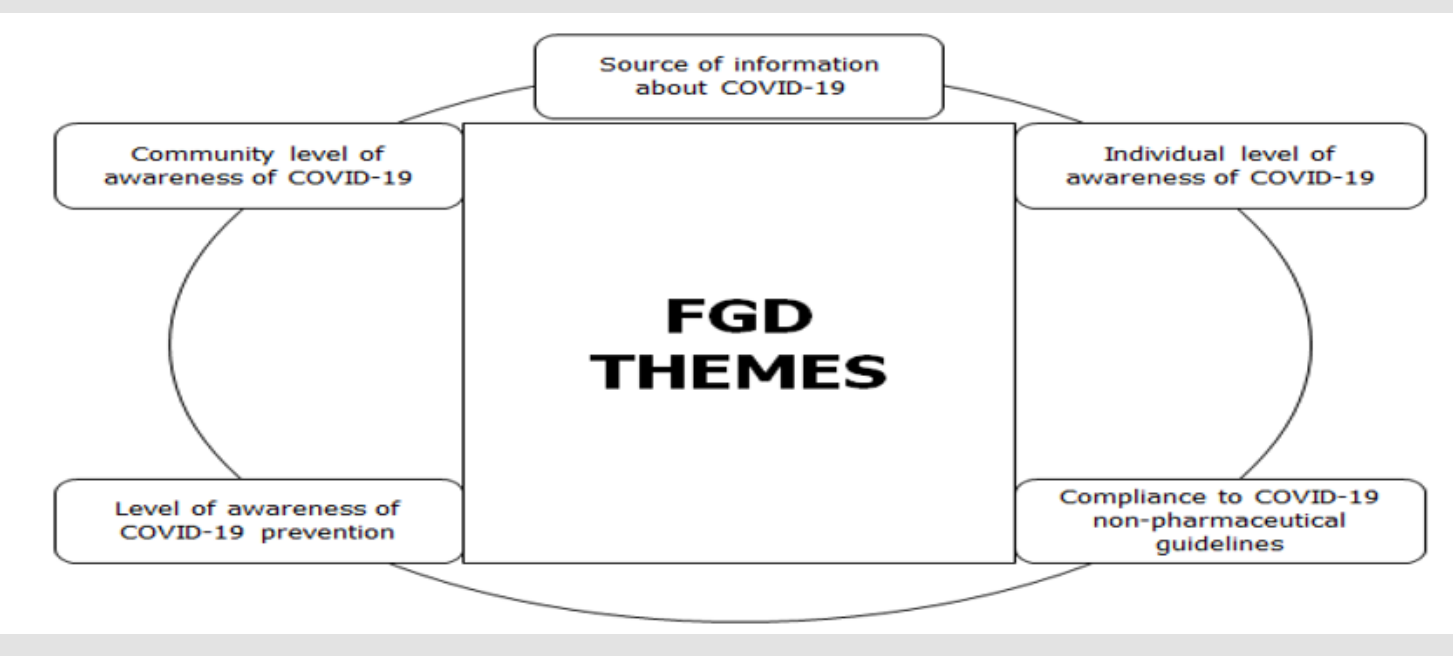

Figure 1: Focal Group Discussion themes obtained from participant's records.

\section{Theme One}

Individual Level of Awareness and Perception of COVID-19:

There is much awareness of what COVID-19 is, among both the women, men and youths of the general population. They described the corona virus as new disease that is harmful to the health which has spread globally. The people have an idea of the cause, where it started and that it affects the respiratory system.

Participants' Responses in Italics: COVID-19 is a disease that is harmful to the health. Affects generally both big and small but mostly to the elderly ones. It affects the respiratory organs and breathing system.

a) It is caused by a virus called Corona virus.

b) From social media, news, and all around we heard that corona virus started in Wuhan China, it started and we know that when there is an outbreak of a deadly disease spreading from one country to the other. We need to be very careful. We were told also from communication and the media that corona virus mostly attacks the respiratory system, ceases breathing and once the breathing is ceased it can also cause death.

However, few of the participants said, it is killing the people of the western world but it is not in Nigeria, rather the government uses it to make money.

a) It is something we heard has been killing people in "Oyibo" (foreign) land but it is not in Nigeria because we have not seen anybody who died from it so it is government that is using it to make money from it.
It is a new sickness that we have been hearing on radio and made government to close our market. we don't believe it's here because we keep our environment clean and we wash our hands regularly, we go to our business and come back safely, we have not heard a single case of covid-19. The signs and symptoms of COVID and its mode of transmission was described by the majority of the people based on what they hear from the media. They stated that it is difficult to actually suspect or know COVID cases since the symptoms are similar to malaria symptoms. They requested to be enlightened on how to know a COVID case. They were able to mention some of the symptoms and how the disease was transmitted.

a) Fever, Cold, Sneezing, Malaria, Cough.

b) They say the person would be coughing then he would be feeling dizzy with tiredness, all these things are things I know, the temperature would be high well.

c) As regard the cause and symptoms of COVID-19, some people believed that it a virus and the symptoms range from fever, cold, shortness of breath and sneezing.

d) The symptoms are like core malaria symptoms like cough, cold, catarrh, and pain Sneezing, fever, cold, difficulty in breathing etc Dry throat, cough, headache.

e) We hardly know a suspected case of covid19 because the symptoms are malaria like hence this the part of the disease that gets me worried. hence, we need more Enlightenment.

f) Through sneezing or contact or somebody that has it touch something. 
g) Disease that goes from person to person by coughing, sneezing, social distancing. We were told to wash our hands through running water. Let us keep social distancing, we should wash our hands very clean.

h) Sneeze, cough, shaking somebody, discussing with somebody, drinking from same cup with some other person. So, we have to give social distance.

i) Sharing of sharp object, Donating of blood, Through handshake, dirty environment.

Shockingly, a participant mentioned Uranium gas to be the cause of COVID.

a) COVID-19 could be caused by Uranium 235. It is a strong gas that kills people when it is emitted into the air.

When asked, 'who is most at risk of contracting the disease?' As a Surprise, most of the people said that everybody is at risk when the person fails to adhere to the COVID prevention guidelines. Majority of them during the FGD sessions mentioned some of the preventive measures. They further stated that they heard that, persons with one form of illness or the other and the elderly are also at risk.

a) That one that fails to honor the rules of COVID-19. As we were asked to keep social distance. All these things are things that would affect you if you were not keeping in touch with what is being said, like keeping social distance, wearing of mask, washing our hands. If we fail to do these things you are at risk of catching this Covid-19.

b) Everybody is likely to contact covid-19 especially when you are not keeping the rules. You are not using your mask, you are not washing your hands, you are not maintaining social distance, you are liable to contact covid-19 especially when you come in contact with those infected with the disease.

c) Covid-19 is not a friend of anybody. Except you are keeping the rules you will not contact it but if you are not keeping the rules, you will contact it.

d) Mostly the elderly ones who have aged with bronchitis, asthma.

e) They say people who is already sick, people who sickness has been in the body for a long time like cough, malaria this kind of people they are quick to get the disease because already their immune system is weak already.

f) The poor who struggle to eat also the rich.

g) People with other health conditions like HIV, hepatitis. Adults and the aged.

h) People with compromised immune system like HIV patients that are not adherent to their medication. i) Elderly people, Pregnant women, Infants, Diabetic, Asthma, Elderly people, those who are 50, 60, 70 years and above.

\section{Theme Two}

Community Level of Awareness of COVID-19: In order to determine the communities' awareness levels during the FGD sessions that involved persons from different communities in the State, this question was posed: "What does the community believe about covid-19 and its existence? Most of the participants stated that most people in their communities do not believe in the existence of COVID-19 and that even if it exists anywhere in or outside the country, it is not in their communities and will not also enter. Even when attempts are made to convince them of the existence of deadly disease in the State, they ask for proof showing that people are indeed suffering from the disease and also proof that the dead cases were as a result of Corona virus infection.

a) There is no known case of COVID-19 in Igbo-Etche Nobody has died from COVID-19.

b) They haven't seen anybody infected with COVID-19.

c) Covid19 is not in Omoku, even if it is real, it's not in this community.

Their reason for not believing that COVID-19 is not real is because they haven't seen anybody infected with COVID-19 in their community. However, some stated that the disease exist, while others believe the contrary.

a) Religious leaders say they have not seen people affected (infected) with COVID-19, and that government is using COVID-19 to stop people from working.

b) $75 \%$ do not believe because they have not seen someone with it.

c) I believe its disease it's for the rich, it's not in Asari toru L.G.A it's not for us.

In fact, the politicians are being accused of using COVID-19 to make money and that it is all world politics.

a) In my community about $75 \%$ do not believe that there is corona virus. They say it's world politics, that the politicians, in the country are using it to make money.

b) If you ask them, they will ask you who and who have contacted the disease in Eleme if there is covid-19. So, we keep on telling them that corona virus is real but they do not believe.

c) So, we keep on telling them that corona virus is real but they do not believe, they said we heard of chicken pox, monkey pox, Ebola, did it enter Eleme at any time, corona virus will not enter. 
The participants advised that there should be more enlightenment campaign to their people because they do not practice social distancing.

a) You see people gumming each other even in the shops because they have not seen anyone affected by it in their environment. I just think they need more of enlightenment to obey COVID-19 protocol.

There is a particular participant who differed from the majority. The participant said most of her community members believe that there is COVID.

a) We have different kind of persons. Some persons believe that covid-19 is not in existence while some other persons believe it's in existence if you rate it by percentage the percentage of those that believe supersedes those that don't believe. So, in my own area many of them believe that there is Covid-19.

There is also the believe by the community members that the virus cannot survive in a hot environment such as Nigeria.

\section{Theme Three}

Source of Information About COVID-19: In order to ascertain the messaging platforms that reach the population, the 12 focus groups were asked to state the different ways they get information concerning COVID-19 and the community as a whole. The participants were able to mention all the messaging platforms and the provision of buckets of water and soap stationed in the church entrance for worshipers to wash their hands.

a) Radio, church, Town Cryer, Pastor, person to person, Text messages from NCDC.

b) Television, Radio, NCDC, neighbors.

c) Social media, SMS from MTN and news.

d) Town crier announced it - made us to understand that we should stop gathering, marriages, burials and all social gathering.

e) The local government also announced it in every village in this LGA, telling us that something like that is happening even in the market.

f) Information in Omagwa community about COVID-19 is through radio.

g) Members of the community (person-to-person).

h) Some religious groups in churches the Pastors give information about COVID-19 and there are buckets of water and soap stationed in the church entrance for worshipers to wash their hands. i) Initially in the market they use to position bucket with water in shops for people to wash their hands to avoid being disturbed by the task force.

j) Information in Rumuokoro about COVID-19 is through radio, TV and posters.

k) Radios, TV and Network and the Media. striking things said: keep social distance, wash your hands and use hand sanitizer.

\section{Whatapp:}

a) When top men die of it, it strikes me. The one that caught my attention is of death of Abba Kyari."

To elicit information on the type of information they have received so far since the pandemic. Most of the participants stated the guidelines and protocols to keep safe. some said, they are told that COVID kills after seven days.

a) How to make sure we keep ourselves safe.

b) That COVID-19 is killing people.

c) They tell people about covid19 about washing of hands and wearing facemask or use of sanitizer so that you no get covid19 and people should not go close to another person.

d) We heard that COVID-19 kills that if you get it after 7 days you will die. This made people to be so afraid.

e) That if you get COVID-19 for three days the person dies. They also announced that we should stop going to where people are full.

The study elicited information on possible information the communities need more that would help to curb the speed of the virus. The participants suggested more information in video clips that shows how the persons affected suffer from the attack of the virus and also the mode of transmission in all the villages. Of course, some form of palliatives to survive with during lockdown for more sensitization programme.

a) If they can a video on how the sickness is affecting people and what it looks like if one contacts the infection. Because I believe seeing is believing.

b) Information on how not to contract COVID-19 even in the market.

c) Grass root enlightenment of the people in their houses.

d) If the government can bring the video to the people in the village to see how the COVID-19 is killing people. They should also provide food for them so that they cannot go out to go and buy food. Give them money in their account so that they will know that they are serious with the COVID-19. 
When asked who they think can provide the most reliable information on COVID-19. The people mentioned the chairmen of the LGAs, the chiefs, pastors and priests whom the people believe in. They also suggested the health facilities and the village health workers who are always in contact with the community members in their houses.

a) Government should pass the information to the local government chairman who will call the chiefs, the chiefs will call his community and enlighten them that there is COVID-19.

b) I think the best way to pass this information is the ministry of health because they know the proper words to use and they also know how to manage people. They should make pastors and priest to be part of the programme because we believe in our pastors and our priest.

c) I think we should make use of our local health workers because they have been in contact with the villagers and know how to relate with them and the English and language they understand. And they relate well with the people.

\section{Theme Four}

Level of Awareness of COVID-19 Prevention: Most of the participants were aware of the preventive measures which they mentioned one after the other. They were also aware that they have to move about with their sanitizers, avoid touching their nose and mouth.
a) Go out with mask.
b) Sanitize your hand.
c) Wash your hands often.
d) Don't go to gathering of more than 50 persons.
e) Provision of mask by government and sanitizer.
f) An implementation of the use of face mask.
g) Sending palliative through clergymen or medical practitioner.

h) Ensure social distance.

i) Uses of hand sanitizer.

j) By following the instruction of the health workers, washing of hands, using hand sanitizers using the mask, avoiding crowded places, with that at least you can prevent it.

k) For me how you can prevent covid19 in church at least they do church services once but now because of crowdedness they divide the church into sessions so that the crowd will not be too much by so doing it will reduce the spread of covid19, this is how we would reduce the spread of covid19, with time the virus will go as it will not affect people.
When asked which of these preventive actions do, they and members of the communities observe to prevent COVID. They claimed to observe the under listed measures

a) Constant hand washing, face mask.

b) Wash hands, mask but no social distance.

c) Hand washing.

d) Bought sanitizer for everyone, social distance.

e) Children are not allowed to play with other children.

f) Use of face mask.

g) No visitors during this period.

h) We hardly move out.

i) Wearing mask, sanitizing the hands washing of hands and social distancing, carrying less passenger.

j) Sterilizing the clippers, also remove quarantine and isolation centers because it scares people.

With the participants being able to mention the above measures, indicates that they are aware of the preventive measure, though one cannot be sure of their claim since most of their community members do not believe that COVID exist in Nigeria and that it can get into their communities. They are also aware of what someone who is suspected positive for COVID-19 should do.

a) Report to the headquarter.

b) Run some test.

c) The person should isolate himself from the people around him and seek for medical attention or call the attention of any medical officer. There should be no self-medication.

d) We will advise the person to self-isolate, if the person doesn't agree we can report the person to the nearest health Centre so they can come and see the person.

\section{Theme Five}

Compliance to COVID-19 Non-Pharmaceutical Guidelines: Compliance to COVID-19 guidelines by persons helps to minimize the spread of corona virus. In order to ascertain the compliance level of the 12 communities where FGD sessions were held, several semi-structured questions were asked during the sessions. These among others were How would you describe the response of your community to the information received on how to prevent COVID-19 and what can government/other stakeholders do to ensure that people adhere to safety guidelines? The participants claimed that their people were scared initially and did not want to contract the disease, therefore obeyed the COVID-19 guidelines such as washing of hands, wearing of masks and observing social distance. Even 
churches closed their sessions on time and burials and marriages were put on hold. More so, they were scared of being arrested by the government or pay any fine. Almost all have returned to normal lifestyles

a) The first time we heard about this sickness, there were some changes like washing of hands, people were so scared. People do not want to contract the disease.

b) They were wearing facemask to the point in the country when the disease was much until it became less, now the disease is coming back again, I believe we will go back to our normal lifestyle that is, putting on our face mask, washing of hands, observing social distance. All burials and marriages will be put on hold very soon.

c) They don't want to be arrested by the government or to pay fine and for their health too. Rapid death, pressure from higher authorities- government was hard on us.

d) Fear, they were so afraid.

e) For the church and market, they comply and with time they close their church sessions.

However, the decline observed in complying with the protocol/ guidelines was when some of the people started doubting the existence of the disease in Nigeria and believed it only exist in the western states. Other reasons of the non-compliance after the initial fear, they have not seen anyone who is suffering from the disease or died as a result of the infection. Rather, it is only reported as News.

a) Because people believe that COVID-19 is not real.

b) Some people don't believe that there is corona virus.

c) People believe that it in oyibo (foreign) land.

d) People are not complying to COVID-19 preventive measures again because they have never seen anyone that is suffering from covid19. They have also not seen anyone that has died from it is just news.

Some of the participants further stated that some of the community members cannot afford the mask and also do not know where to get it. They reported that people do not wear mask in occasions even in the presence of COVID-19 protocol personnel who are assigned to cover the events to ensure compliance.

a) Some can't afford mask, some don' t knows where to get it, something you can't see where to buy and you can't afford it's hard to get it.

b) I went for one burial being covered by covid-19 personnel but I observed that nobody was putting on face mask. In the presence of covid-19 personnel, people were not putting face mask because the covid-19 personnel were not wearing face mask.
The participants stated that some persons began to associate the illness to 'Rich' and also a campaign strategy for the politicians. The people were harassed by the police and some Law enforcement agencies turned the COVID-19 issue to a money-making venture.

a) They think is a big man issue for that reason they find it difficult to believe.

b) Campaign by politicians even when they asked churches to close.

c) There was a time when police were on the road harassing people without face mask. People started wearing their face mask even those going to farm.

d) Law enforcement agencies after a while started to extort people.

Question on what government/stakeholders can do to ensure that people adhere to safety guidelines, the participants made these suggestions

a) Government should engage the communities from time to time to avail them the opportunity to ask questions and enlighten them.

b) Volunteers should be brought to market to enforce some of the guidelines

c) They should provide mask, sanitizers and other essential things

d) Government should train people to go round even in schools and markets to educate people.

e) Government should help in decontamination of public places.

f) Provision of sanitizers and masks

g) Changing the name because they believe anyone that goes to isolation Centre doesn't come back, they should use a friendly name.

h) I think the government needs to sensitize them, even up till now some people do not believe that there is a sickness like that in Nigeria. So, the government needs to sensitize their minds. If they can do a video on how the sickness is affecting people and what it looks like if one contacts the infection. Because I believe seeing is believing.

i) If the government can bring the video to the people in the village to see how the COVID-19 is killing people. They should also provide food for them so that they cannot go out to go and buy food. Give them money in their account so that they will know that they are serious with the COVID-19.

j) Government should organize a programme in the entire village in the programme they should show videos of how 
COVID-19 can be contacted and show someone with COVID-19 is affected. Before the programme there should be a lock down and during this lock down, they should give them money for people to manage and see the programme. So that they can believe that there is COVID-19.

k) Government should introduce measures to reduce hunger because the more lockdown the more hardship and suffering and also finding vaccine can end the pandemic instead of imposing lockdown."

\section{Discussion}

We explored the awareness and perceptions of women, men and youths towards COVID-19, major sources and message platforms and as well as public compliance to COVID-19 nonpharmaceutical guidelines. The study showed good knowledge and high awareness of COVID-19 among participants. The origin, transmission, cause and prevention of COVID-19 were well expressed by the discussants, resulting from media information. This finding supports reports from previous investigations reports [50]. Although the result differed from the finding of Christopher et al., 2020, where poor awareness of the disease was reported in northern Nigeria. However, participants believe that though the virus exist, but thrives in the western world, it cannot survive in the hot Nigerian environment and there are no proof of infected or persons known to them. Unlike in the study conducted by Hong et al. 2020, there was lack of self-perceived risk of contracting COVID-19 (Oyeyemi et al., 2020) among the community people, as participants seemed to think that the COVID-19 an exaggerated health issue [51].

Radio, television, Nigeria Centre for Disease Control (NCDC) text messages, banners and posters, town-crier and person-toperson were the prominent information platforms and sources participants reported to get their information about COVID-19, while a few mentioned social media platforms such as Facebook, and WhatsApp. Studies have found them to have little or no impact on behavioural change [52]. However, in emergency settings such as the COVID-19 pandemic times, information dissemination is not essential, but prompt, appropriate quality information to the public using behavioural influencing platforms remains must be strategic in curtailing highly infectious disease such as CVID-19 [53]. According to Al-Dmour (2020), better consideration of the effects of the use of social media communication on public health protection against COVID-19 while taking public health awareness and behavioural changes into account as mediators in health promotion strategy plan. As strategic use of social media platforms could most probably positively influence public health awareness, behavioural changes and community protection against COVID-19 in cross-cultural context. Similarly, Obi-Ani et al. found that although social media platforms are noted with higher likelihood of abuse, Facebook, Twitter, WhatsApp, blogs, online newspapers, and YouTube where the used by the populace outside the World Health Organizations (WHO), NCDC, and State Institutions. The paper concludes that the significance of social media outlets cannot be undermined regarding dissemination of COVID-19 information [54]. Irrespective of credibility concerns, social media platforms have been found to be a strong tool for creating awareness, educate and influence behaviours, convert information to daily discussions and cost-effective in public health risk communication. Noting that public perceptions are shaped depending on how information is communicated [55].

Non-pharmaceutical interventions (NPIs) most probably represent the simplest, low-cost, effective ways of minimising COVID-19 transmission and other highly infectious disease. NPIs were found to significantly curtail the COVID-19 pandemic across mostcountries of the world. In this study, we observed highawareness of NPIs such as use of hand sanitizers, avoid touching of the nose and mouth, and ensuring social distance among participants. Some participants knew who to call for suspected case, not allowing their children play with other children, and non-permission of visitors during the period of lockdown in the first wave of COVID-19 in Nigeria. However, compliance to the NPI measures was mostly observed during the first wave because of the fear of Government and not the perceived risk of infection, as citizens wear mask only to pass and do business at public places not for self-protection or risk reduction. Spuriously, while COVID-19 cases and deaths continue to rise, public compliance to NPI continues to decline, necessitating the speedy assent to COVID-19 Health Protection Regulations 2021 by the Nigerian present. The regulation which makes mask wearing at public places compulsory, restriction to limited number person at gatherings, compulsory isolation and quarantine when necessary among other guidelines could be justifiable by public health empirical evidences (Bhatt et al., 2020; Marotta et al., 2021; Matuschek et al., 2020; Xu et al., 2020) but may conflict with public compliance for some behavioural, sociocultural, and economic factors such as inconvenience (Kantor \& Kantor, 2020), beliefs about infection transmission, perceived individual risk, and stigma (Teasdale et al., 2014; Williams et al., 2020), affordability of some NPIs commodities, poor communication strategy, and public distrust to Government policies.

\section{Recommendations and Implication on Policy Formulation}

Higher awareness of COVID-19 virus does not necessarily translate to positive public health behavioural change and compliance to NPIs. Understanding what influences public compliance to non-pharmaceutical interventions such as hand and respiratory hygiene, mask wearing and social distancing could help to institute informed, effective, acceptable and evidencebased as well as implementable and enforceable public health regulations and policies. The general public actively evaluate non- 
pharmaceutical interventions in terms of their perceived necessity and risk, efficacy, acceptability, affordability, and feasibility and sustainability. We recommend that strategic risk communication and community engagement activities of COVID-19 curtailment be funded and given priority. Targeted contents should be disseminated consistently to the public through social media platforms, as this is found to be the most preferred source of information channel. For positive public health behavioural change at the community level, the together with public health experts, opinion leaders and social influencers - celebrities, traditional and religious leaders should lead public discuss about COVID-19 on media platforms. Study participants raised concerns of stigma and discriminatory communication; risk communication languages should be more friendly and appealing to the public. For example, rather than using the term "Isolation center," “Care centers" should be an alternative.

To raise the perceived risk level and public believe of the existence of COVID-19, documentary of national and global deaths and hospitalisation should be considered and made publicly available in different indigenous languages. Public trust remains essential; hence, consistent and coherent policies by government and her regulatory authorities is most vital. Making mask wearing without availability framework could be counterproductive. The State can make facemask wearing compulsory at public places by ensuring that the authorities of public place - schools, churches, parks, markets, banks, business places, etc. provides face mask at the entering points. Public health partners, NGOs and individuals could support in this regard. To curtail possible outbreak of mask related microbial surge, continues complementary public education on appropriate use of mask likely to make impact on behavioural change, when masks are a made available to all.

\section{Funding}

None.

\section{Conflict of Interest}

The authors declare no conflict of interest regarding this manuscript.

\section{Participants and Public Involvement}

Patients and the public were not involved in the designing, conduct, reporting, and dissemination of the study.

\section{Participant Consent for Publication}

Not required.

\section{Availability of Data}

Data are available upon reasonable request. Ethical restrictions related to participant confidentiality prohibit the authors from making the data set publicly available. During the consent process, participants were explicitly guaranteed that the data would only be seen my members of the study team.

\section{References}

1. Akan H, Gurol Y, Izbirak G, Ozdatl S, Yilmaz G (2010) Knowledge and attitudes of university students toward pandemic influenza: A crosssectional study from Turkey. BMC Public Health 10(1): 413.

2. Al Dmour H, Masadeh R, Salman A, Abuhashesh M, Al Dmour R (2020) Influence of social media platforms on public health protection against the COVID-19 pandemic via the mediating effects of public health awareness and behavioral changes: Integrated model. Journal of Medical Internet Research 22(8): e19996.

3. Al-Surimi K, Khalifa M, Bahkali S, EL Metwally A, Househ M (2017) The potential of social media and internet-based data in preventing and fighting infectious diseases: From internet to twitter. In Advances in Experimental Medicine and Biology 972: 131-139.

4. Baum NM, Goold SD, Jacobson PD (2009) Listen to the people: Public deliberation about social distancing measures in a pandemic. American Journal of Bioethics 9(11): 4-14.

5. Benetoli A, Chen TF, Aslani P (2018) How patients' use of social media impacts their interactions with healthcare professionals. Patient Education and Counseling 101(3): 439-444.

6. Bhatt N, Bhatt B, Gurung S, Dahal S, Jaishi AR (2020) Perceptions and experiences of the public regarding the COVID-19 pandemic in Nepal: A qualitative study using phenomenological analysis. BMJ Open 10(12): $1-11$.

7. Bo Y, Guo C, Lin C, Zeng Y, Li HB, et al. (2021) Effectiveness of nonpharmaceutical interventions on COVID-19 transmission in 190 countries from 23 January to 13 April 2020. International Journal of Infectious Diseases 102: 247-253.

8. (2020) CDC. How Coronavirus Spreads / CDC. In centers for Disease Control and Prevention, p. 1-2.

9. Chowdhury R, Heng K, Shawon MSR, Goh G, Okonofua D, et al. (2020) Dynamic interventions to control COVID-19 pandemic: a multivariate prediction modelling study comparing 16 worldwide countries. European Journal of Epidemiology 35(5): 389-399.

10.(2016) CIOMS. International Ethical Guidelines for Health-related Research Involving Humans Fourth Edition. Geneva. In Biomedical Research.

11. Coffey A, Atkinson P (1996) Making Sense of Qualitative Data. In: Coffey A, Atkinson P (Eds.)., SAGE Publications Inc, USA.

12. Creswel JW (2009) Qualitative, quantitative, and mixed methods approaches. Research Design Qualitative Quantitative and Mixed Methods Approaches.

13. Davies NG, Kucharski AJ, Eggo RM, Gimma A, Edmunds WJ, et al. (2020) Effects of non-pharmaceutical interventions on COVID-19 cases, deaths, and demand for hospital services in the UK: a modelling study. The Lancet Public Health 5(7): e375-e385.

14. Flaxman S, Mishra S, Gandy A, Unwin HJT, Mellan T, et al. (2020) Estimating the effects of non-pharmaceutical interventions on COVID-19 in Europe. Nature 584(7820): 257-261.

15. Freberg K, Palenchar MJ, Veil SR (2013) Managing and sharing H1N1 crisis information using social media bookmarking services. Public Relations Review 39(3): 178-184.

16. Gralton J, Tovey E, McLaws ML, Rawlinson WD (2011) The role of particle size in aerosolised pathogen transmission: A review. In Journal of Infection 62(1): 1-13.

17. Guest G, Namey E, McKenna K (2017) How Many Focus Groups Are Enough? Building an Evidence Base for Nonprobability Sample Sizes. In Field Methods 29(1): 3-22.

18. Hager E, Odetokun IA, Bolarinwa O, Zainab A, Okechukwu O (2020) Knowledge, attitude, and perceptions towards the 2019 Coronavirus Pandemic: A bi-national survey in Africa. PLoS ONE 15(7): 1-13. 
19. Hong SH, Hwang H, Park MH (2021) Effect of COVID-19 nonpharmaceutical interventions and the implications for human rights. International Journal of Environmental Research and Public Health 18(1): 217.

20. Ilesanmi O, Afolabi A (2020) Perception and practices during the COVID-19 pandemic in an urban community in Nigeria: A cross-sectional study. Peer J 8: e1008.

21. Kantor BN, Kantor J (2020) Non-pharmaceutical Interventions for Pandemic COVID-19: A Cross-Sectional Investigation of US General Public Beliefs, Attitudes, and Actions. Frontiers in Medicine 7: 384.

22. Kennedy DM, Zambrano GJ, Wang Y, Neto OP (2020) Modeling the effects of intervention strategies on COVID-19 transmission dynamics. Journal of Clinical Virology 128: 104440.

23. Kitzinger J (1995) Qualitative Research: Introducing focus groups. BM] 311(7000): 299

24. Korda H, Itani Z (2013) Harnessing Social Media for Health Promotion and Behavior Change. Health Promotion Practice 14(1): 15-23.

25. Lai S, Ruktanonchai NW, Zhou L, Prosper O, Luo W, et al. (2020) Effect of non-pharmaceutical interventions to contain COVID-19 in China. Nature 585(7825): 410-413

26. Lee M, Kang BA, You M (2021) Knowledge, attitudes, and practices (KAP) toward COVID-19: a cross-sectional study in South Korea. BMC Public Health 21(1): 1-10.

27. Li Q, Guan X, Wu P, Wang X, Zhou L, et al. (2020) Early Transmission Dynamics in Wuhan, China, of Novel Coronavirus-Infected Pneumonia. New England Journal of Medicine 382(13): 1199-1207.

28. Liu J, Liao X, Qian S, Yuan J, Wang F, et al. (2020) Community transmission of severe acute respiratory syndrome Coronavirus 2, Shenzhen, China, 2020. Emerging Infectious Diseases 26(6): 1320-1323.

29. Marotta C, Nacareia U, Estevez AS, Tognon F, Genna GD, et al. (2021) Mozambican Adolescents and Youths during the COVID-19 Pandemic: Knowledge and Awareness Gaps in the Provinces of Sofala and Tete. Healthcare (Basel, Switzerland) 9(3): 321.

30. Matuschek C, Moll F, Fangerau H, Fischer JC, Zänker K, et al. (2020) Face masks: Benefits and risks during the COVID-19 crisis. In European Journal of Medical Research 25(1): 1-8.

31. Mays N, Pope C (1995) Rigour and qualitative research. In British Medical Journal 311(6997): 109-112.

32. Mitchell T, Dee DL, Phares CR, Lipman HB, Gould LH, et al. (2011) Nonpharmaceutical interventions during an outbreak of 2009 pandemic influenza a (H1N1) virus infection at a large public university, April-May 2009. Clinical Infectious Diseases 52(1).

33. Moser A, Korstjens I (2018) Series: Practical guidance to qualitative research. Part 3: Sampling, data collection and analysis. European Journal of General Practice 24(1): 9-18.

34. Muanya C, Onyedika Ugoeze N (2021) COVID-19 defaulters risk jail as Buhari signs regulations | The Guardian Nigeria News - Nigeria and World News-Nigeria. The Guardian Nigeria News - Nigeria and World News.

35. (2020) NCDC. Infection Prevention and Control and Conirmed Cases of COVID-19. 1(Version 2), p. 2-14.

36. Obi Ani NA, Anikwenze C, Isiani MC (2020) Social media and the Covid-19 pandemic: Observations from Nigeria. Cogent Arts and Humanities 7(1).

37. Okunade K (2018) January-March 2018 An Official Publication of The National Postgraduate Medical College of Nigeria. Nigerian Postgraduate Medical Journal, p. 19-26.
38. Oleribe 0, Ezechi O, Osita Oleribe P, Olawepo O, Musa AZ, et al. (2020) Public perception of COVID-19 management and response in Nigeria: A cross-sectional survey. In BMJ Open 10(10): 1-7.

39. Oyeyemi O, Oladoyin V, Okunlola O, Mosobalaje A, Oyeyemi I, et al. (2020) COVID-19 pandemic: Nigerians' knowledge, perception and adherence to preventive measures. Preprint 7: 1-10.

40. Pan A, Liu L, Wang C, Guo H, Hao X, et al. (2020) Association of Public Health Interventions with the Epidemiology of the COVID-19 Outbreak in Wuhan, China. JAMA - Journal of the American Medical Association 323(19): 1915-1923.

41. Porumbescu GA (2016) Linking public sector social media and e-government website use to trust in government. Government Information Quarterly 33(2): 291-304.

42. Pulido CM, Redondo Sama G, Sordé Martí T, Flecha R (2018) Social impact in social media: A new method to evaluate the social impact of research. PLoS ONE 13(8): e0203117.

43. Reuben RC, Danladi MMA, Saleh DA, Ejembi PE (2021) Knowledge, Attitudes and Practices Towards COVID-19: An Epidemiological Survey in North-Central Nigeria. Journal of Community Health 46(10): 457-470.

44. Seale H, Dyer CEF, Abdi I, Rahman KM, Sun Y, et al. (2020) Improving the impact of non-pharmaceutical interventions during COVID-19: examining the factors that influence engagement and the impact on individuals. BMC Infectious Diseases 20(1): 607

45. Tates K, Zwaanswijk M, Otten R, Van Dulmen S, Hoogerbrugge PM, et al. (2009) Online focus groups as a tool to collect data in hard-to-include populations: Examples from paediatric oncology. BMC Medical Research Methodology 9(1): 15.

46. Teasdale E, Santer M, Geraghty AWA, Little P, Yardley L (2014) Public perceptions of non-pharmaceutical interventions for reducing transmission of respiratory infection: Systematic review and synthesis of qualitative studies. In BMC Public Health 14(1): 589.

47. Tritter JQ, Landstad BJ (2019) Focus groups. In Qualitative Research in Health Care 8(5): 57-66.

48. (2020) UNICEF, IFRC, \& WHO. Focus group discussion guide for communities. Unicef, p. 1-9.

49. (2020) UXalliance. Conducting remote online focus groups in times of COVID-19 | by UXalliance | Medium. In Medium.

50. Van Doremalen N, Bushmaker T, Morris DH, Holbrook MG, Gamble A, et al. (2020) Aerosol and Surface Stability of SARS-CoV-2 as Compared with SARS-CoV-1. New England Journal of Medicine 382(16): 1564-1567.

51. (2020) WHO. Coronavirus disease 2019 (COVID-19) Situation Report 51. Geneva, World Health Organization.

52. Williams SN, Armitage CJ, Tampe T, Dienes K (2020) Public perceptions and experiences of social distancing and social isolation during the COVID-19 pandemic: A UK-based focus group study. BMJ Open 10(7).

53. Wilson NM, Norton A, Young FP, Collins DW (2020) Airborne transmission of severe acute respiratory syndrome coronavirus-2 to healthcare workers: a narrative review. In Anaesthesia 75(8): 1086-1095.

54.https://www.who.int/news-room/commentaries/detail/modesof-transmission-of-virus-causing-covid-19-implications-for-ipcprecaution-recommendations

55. Xu H, Gan Y, Zheng D, Wu B, Zhu X, et al. (2020) Relationship Between COVID-19 Infection and Risk Perception, Knowledge, Attitude, and Four Nonpharmaceutical Interventions During the Late Period of the COVID-19 Epidemic in China: Online Cross-Sectional Survey of 8158 Adults. Journal of Medical Internet Research 22(11): e21372. 
ISSN: 2574-1241

DOI: 10.26717/BJSTR.2021.36.005928

Golden Owhonda. Biomed J Sci \& Tech Res

(C) (P) This work is licensed under Creative

Submission Link: https://biomedres.us/submit-manuscript.php

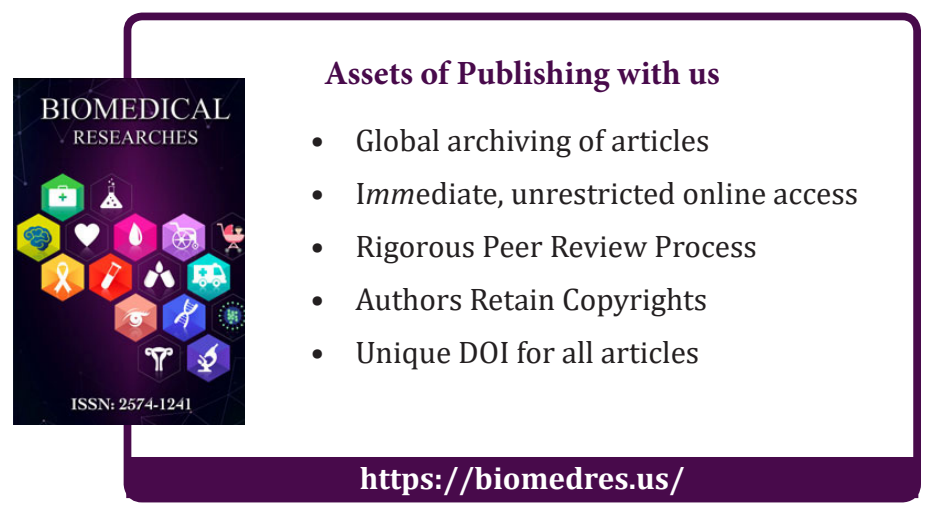

